and the surface; and (4) the difference between the surface-soil minimum and that of the air above it These determinations are necessary because:-(i) The radiation from the soil on calm, clear nights is a function of the relative humidity (A. Angström, Smithsonian Misc. Coll., $6_{5}$ No. 3); (ii) the radiation from the soil can be accounted for in balancing the upward conduction and the latent heat of freezing, the residue only cooling the soil; and (iii) the temperature of the surface soil rapidly falls sufficiently below the temperature of the 4-in. depth to make the conduction from this depth balance the radiation; after this the surface temperature falls no faster than that of the 4-in. depth.

Franklin has also noted rapid changes in underground temperature (6-in. depth) after heavy rain. This he attributes to the receding water drawing hot or cold air into the soil, but it is scarcely possible that the volume of air thus drawn in could supply or abstract sufficient heat to account for the observed differences. These latter are in the direction which would be expected from the time of the day when the readings were taken; and while the re-aëration of the soil may have slightly increased the temperature changes, it is unlikely that it had a predominating influence.

B. A. KEEN.

\section{LUBRICATION AND LUBRICANTS}

THE meeting of the Physical Society held on November 28 was devoted to a discussion on the subject of lubrication, suggested by a paper on "Oili. ness and Lubrication" by Mr. R. M. Deeley, sent by the Committee on Lubrication. Other contributors included Dr. Stanton, Principal Skinner, Messrs. W. B. Hardy, Dorman, Southcombe, Martin, Archbutt, Edser, and Dr. H. S. Allen.

In the consideration of lubrication problems a clear distinction must be made between two prevailing conditions, viz.: (I) Those in which the solid surfaces are completely separated by a film of oil, as occurs in the lubrication of cylindrical journals and their bearings working under moderate pressures, revolving at high speed, and supplied with abundance of oil; and (2) those in which, owing to the shape or condition of the surfaces, the kind of motion, high bearing pressure, low speed, or an inadequate supply of oil, the oil-film cannot form completely, or becomes broken, and the solid surfaces come into contact. In (I) the friction is entirely due to the viscosity of the oil, as proved by Beauchamp Tower and Osborne Reynolds. Engineers have Reynolds's theory to guide them in the design of bearings so as to secure fluid friction, and it is possible by determining the viscosity and chemical characteristics of an oil to form a sound opinion as to its suitability to meet the required conditions. In (2) the circumstances are quite different. Lubricating value is then found to depend upon some property which is quite distinct from viscosity, and has been called "oiliness."

In opening the discussion Dr. Stanton referred to experiments recently made at the National Physical Laboratory for the Lubrication Committee with the lanchester worm-gear testing machine, in which working pressures of several tons per square inch are developed, showing that in the case of all the mineral oils tested the lubrication at a certain temperature suddenly became imperfect, the friction irregular, and the efficiency of the gear fell off. With fixed oils no such "breaking-down" point was observed under the conditions of the tests, and it was found that by adding quite a small percentage of fatty oil to a mineral oil the breaking-down point, No. 26 I 8 , VOL. IO 4$]$ though not obliterated, occurred at a higher temperature.

Mr. Deeley described and exhibited a small handdriven machine which he had invented for the purpose of measuring the oiliness of lubricants under conditions of metallic contact. Three flat-ended metal studs, each $5 / 32^{\prime \prime}$ in diameter, secured concentrically as feet to a metal disc, rested upon another metal disc which could be slowly rotated. The upper disc could be weighted as desired, and actuated a spindle to which a spiral spring and a recording finger were attached. The lower disc, when rotated, carried the studs and upper disc with it by friction until the stress in the spring caused the surfaces to slip, when the pointer gave the frictional resistance, oscillations being damped by gearing the spring and pointer to a train of wheels. Experiments made with this machine showed that the static friction depended upon the nature of the metal surfaces in contact as well as upon the oil, and the fatty oils which in practice are found to be the best lubricants gave lower static coefficients than the mineral oils. Mr. Deeley's view is that the oil, or some constituent of it, enters into physico-chemical union with the comparatively rigid metallic surface, forming a composite film having the yielding nature of velvet-pile, and that the best lubricants are those which produce the most easily sheared contact films.

Dr. Allen directed attention to the important work of Irving Langmuir on surface films, and suggested that the property of "oiliness" depends upon the chemical forces called into play between the active part of the oil molecule and the solid surface of the bearing, and not only on the nature of the lubricant, but also on that of the solid surfaces with which the liquid is brought into contact.

Mr. W. B. Hardy referred to the work carried on by his son and himself, and discussed by them in the Philosophical Magazine of July last. In the apparatus they used there was only one point of contact between the solid surfaces, which consisted at first of a curved watch-glass on a flat glass plate, and latterly of similarly shaped surfaces of bismuth. The force measured was that necessary to cause the curved surface to slide over the plate when lubricated by the films formed by individual chemical substances representative of various groups of chemical compounds. The authors concluded that the true function of a lubricant was to reduce the energy of the surface, and thereby to reduce the capacity for cohesion and the resistance to slip when two composite surfaces are applied one to the other. This, in the opinion of the present writer, is the conclusion to which all recent work leads, and the problem before the chemist is to determine in what manner the molecular structure of the chemical compounds in lubricants determines their "oiliness."

The practical side of the problem cannot, however, be neglected, and it is necessary to experiment with commercial lubricants acting between such dissimilar metal surfaces as are used in the construction of machines, in order to obtain the information which engineers require to guide them in the lubrication of machinery. Mr. Southcombe's observation that the interfacial tension between oil and water and oil and mercury is much higher with mineral oils than with fatty oils, and that the addition of a very little free oleic acid to a mineral oil greatly lowers the surface tension, is of great importance. It appears that by adding I per cent. of free fatty acid to a mineral oil the lubricating power is increased as much as by adding a verv much larger percentage of fatty oil. The emulsifying properties can also be materially modified by the addition of fatty acids. 